\title{
Effect of Cryptobia salmositica-induced anorexia on feeding behavior and immune response in juvenile rainbow trout Oncorhynchus mykiss
}

\author{
Adrian Chin, Fu Ci Guo, Nicholas J. Bernier, Patrick T. K. Woo* \\ Department of Zoology, University of Guelph, Guelph, Ontario N1G 2W1, Canada
}

\begin{abstract}
At $10^{\circ} \mathrm{C}$, rainbow trout Oncorhynchus mykiss ( $\mathrm{n}=13$ per group) infected with Cryptobia salmositica Katz, 1951 became anorexic at 3 wk post-infection (w.p.i.), with feed-intake decreasing significantly from 1.33 to $0.94 \%$ body weight (b.w.). Anorexia was most severe at 4 w.p.i. $(0.80 \%$ b.w.), coinciding with peak parasitemia $\left(9.2 \times 10^{6}\right.$ parasites $\left.\mathrm{ml} \mathrm{blood}^{-1}\right)$ and anemia. At 8 w.p.i., fish had recovered their appetite although they still had contained detectable parasites $\left(6.8 \times 10^{5}\right.$ parasites $\mathrm{ml}^{-1}$ ) and were anemic (pack cell volume, $\mathrm{PCV}$, of $24.4 \%$ ). However at $5^{\circ} \mathrm{C}$, anorexia occurred at 5 w.p.i. $(0.81 \%$ b.w.), and was most severe at 7 w.p.i. $(0.40 \%$ b.w.). At 8 w.p.i. ( $0.43 \%$ b.w.), fish displayed high parasitemia $\left(4.6 \times 10^{6}\right.$ parasites $\left.\mathrm{ml}^{-1}\right)$ and low PCV $(10.8 \%)$. Fish at $5^{\circ} \mathrm{C}$ had lower gastric evacuation (GE) rates $\left(\mathrm{GE}_{48 \mathrm{~h}}\right)$ than $10^{\circ} \mathrm{C}$ fish, however there were no differences between infected and naïve fish at both temperatures. Before anorexia, there was no significant correlation between mean share of meal (MSM, a measure of how food was partitioned within a group) and coefficient of variation in feeding but this became significant during anorexia $(p=0.02$ and $p=0.0002$ at 10 and $5^{\circ} \mathrm{C}$ respectively). Significant correlations were detected between b.w. and MSM before onset of anorexia at $10^{\circ} \mathrm{C}(\mathrm{p}=0.005)$ and $5^{\circ} \mathrm{C}(\mathrm{p}=0.02)$; this was maintained at $10^{\circ} \mathrm{C}(\mathrm{p}=0.001)$ but not at $5^{\circ} \mathrm{C}$ $(\mathrm{p}=0.98)$. Fish on an anorexic diet $\left(0.93 \%\right.$ b.w.) responded well at $10^{\circ} \mathrm{C}$ to a live C. salmositica vaccine; this could partly be due to constant antigenic stimulation by the live vaccine.
\end{abstract}

KEY WORDS: Anorexia - Cryptobia salmositica · Temperature - Gastric evacuation - Feeding hierarchies $\cdot$ Immune response $\cdot \mathrm{X}$-radiography $\cdot$ Vaccine

\section{INTRODUCTION}

Cryptobia salmositica Katz, 1951, a protozoan hemoflagellate (Kinetoplastida) causes salmonid cryptobiosis which can result in morbidity and mortality. Clinical signs of disease are microcytic and hypochromic anemia, exophthalamia, abdominal distension with ascites, splenomegaly and hepatomegaly. Anorexia is also a consistent sign of the disease and immunodepression has been reported (see Woo 2001).

Anorexia, i.e. reduction in food consumption (Symons 1985), is a characteristic response of fishes to viral (Damsgard et al. 1998), bacterial (Neji \& de la Noue 1988, Pirhonen et al. 2000) and parasitic (Thomas \& Woo 1992, Dezfuli et al. 2003) diseases. It occurs in cryptobiosis, and its onset has been associated with the acute phase of the disease, which is characterized by high parasitemia and severe anemia in rainbow trout (Li \& Woo 1991, Thomas \& Woo 1992). Conversely, a return of appetite has been associated with the establishment of an immune response against the pathogen that significantly reduces the parasitemia and anemia. Li \& Woo (1991) showed anorexia to be beneficial, as it lowers plasma protein, thus reducing parasitemia and, consequently, the severity of the disease (Woo 1979).

Anorexia also occurs in fishes in response to environmental, social and physical stressors (Schreck et al. 1997, Bernier \& Peter 2001a). Stress activates the hypothalamic-pituitary-interrenal (HPI) axis, resulting in the release of adrenocorticotropin hormone (ACTH) by the pituitary, the primary signal that initiates the synthesis and secretion of cortisol from interrenal cells 
(Wendelaar Bonga 1997). This leads to elevated cortisol levels characteristic of a primary stress response (Barton \& Iwama 1991). The corticotropin-releasing factor (CRF) and related neuropeptides are important in regulating the HPI axis in the hypothalamus (Lederis et al. 1994), and appear to be involved in mediating the appetite-suppressing effects of stressors (Bernier \& Peter 2001b). In mammals, there is also strong evidence that CRF-related peptides can regulate gastric evacuation and mediate stress-related alterations in the motor functions of the gut. Although Cryptobia salmositica-infected rainbow trout have high circulating cortisol levels (Laidley et al. 1988) and are characteristically anorexic, the impact of this parasitic infection on their gastric-evacuation rate has not been documented.

Feeding hierarchies have been reported for salmonids in both laboratory and field studies (Sloman \& Armstrong 2002). Size is an important factor (Sloman \& Armstrong 2002), and larger fish are more dominant in terms of access to food and subsequent growth rate. Much evidence in studies on mammals and fishes implicates an increased susceptibility to disease connected with a subordinate status (Peters et al. 1988, Maule et al. 1989, Ebbersen et al. 1992, Padgett et al. 1998). This may be due to elevated cortisol levels in subordinates, since cortisol is known to suppress the immune response (Schreck 1996). However, there have been virtually no studies on the impact of disease on feeding hierarchies in fishes.

Humoral and cell-mediated immune responses are important mechanisms against cryptobiosis (Ardelli \& Woo 2002, Mehta \& Woo 2002). Live vaccine (attenuated Cryptobia salmositica) protects rainbow trout (Li \& Woo 1995, Mehta \& Woo 2002), chinook salmon (Staines \& Woo 1997), brook charr (Ardelli \& Woo 1997), and Atlantic salmon (Ardelli \& Woo 2002) from this disease. Neutralizing, agglutinating, and complement-fixing antibodies have been detected in infected and vaccinated rainbow trout (Jones \& Woo 1987, Li \& Woo 1995, Mehta \& Woo 2002). Cell-mediated immune responses have been demonstrated, including delayed-type hypersensitivity reactions (Thomas \& Woo 1990, Feng \& Woo 1996), inhibition of macrophage migration (Thomas \& Woo 1990), stimulation and growth of peripheral leukocytes with concovalin A (Ardelli \& Woo 2002), and increased respiratory bursts killing macrophages in the head kidney (Mehta \& Woo 2002).

Infected rainbow trout show a significantly lower humoral immune response to sheep red-blood cells (sRBC) (Wehnert \& Woo 1981, Thomas \& Woo 1992) and Yersinia ruckeri (Jones et al. 1986), and vaccination against yersiniosis has been unsuccessful in acutely infected fish individuals (Jones et al. 1986). It has been hypothesized that the immunodepression is probably the result of antigenic competition, and Thomas \& Woo (1992) showed that anorexia contributes to immunodepression.

The objectives of this present study were (1) to compare the onset and severity of anorexia at 5 and $10^{\circ} \mathrm{C}$ and its effect on gastric evacuation and feeding hierarchy in Oncorhynchus mykiss, and (2) to investigate the effect of an anorexic diet on their humoral and cellmediated immune response to live Cryptobia salmositica vaccine.

\section{MATERIALS AND METHODS}

Source of Cryptobia salmositica. Pathogenic C. salmositica (cloned Substrain T4) was initially isolated from a leech vector on Vancouver Island (Woo 1978). Pathogenicity has been maintained through serial passage in susceptible salmonids kept at $10^{\circ} \mathrm{C}$, and the attenuated C. salmositica (vaccine strain) is maintained at $10^{\circ} \mathrm{C}$ in minimum essential media (MEM) supplemented with Hank's salt, L-glutamine, 25 mM 4-(2-hydroxyethyl)-1-piperazineethanesulphonic (HEPES) buffer and $20 \%$ fetal bovine serum (Gibco) (Woo \& Li 1990).

Fish. Rainbow trout Oncorhynchus mykiss embryos were purchased from Springs Trout Farm (Thamesford, Ontario) and raised in the laboratory. At $8 \mathrm{mo}$ of age, 114 fish ( 30 to $89 \mathrm{~g}$ ) were divided into 7 groups (A to $G)$. There were no significant differences ( $p>0.05)$ in weight between groups. All fish in Groups A to D $(\mathrm{n}=13$ per group) were fin-clipped for identification in the gastric evacuation and feeding hierarchy study. Fish in Groups A and C were infected with Cryptobia salmositica, while fish in Groups B and D served as naïve controls. Groups A and B were maintained at $10^{\circ} \mathrm{C}$ and Groups $\mathrm{C}$ and D at $5^{\circ} \mathrm{C}$. Group E ( $\mathrm{n}=36$ ) was used to quantify parasitemia and PCV values during the course of infection at $10^{\circ} \mathrm{C}$. Groups F and G $(n=13$ group $^{-1}$ ) were used to investigate the effect of anorexia on immune response to the live vaccine at $10^{\circ} \mathrm{C}$. Group $\mathrm{F}$ was fed a quantity of food (anorexic diet) similar to that eaten by Group A when the latter became anorexic. Groups G and B were pair-fed. All groups were maintained in individual $125 \mathrm{l}$ tanks with aerated recirculated well-water and an equatorial lighting regime. Fish were acclimated to their treatment tanks for $2 \mathrm{wk}$ before the experiments began.

Expt 1: Food consumption, gastric evacuation and feeding hierarchy in juvenile rainbow trout infected with pathogenic Cryptobia salmositica at 10 and $5^{\circ} \mathrm{C}$. Experimental design: The fish were fed once a day (between 09:00 and 11:00 h) with commercial dry trout pellets (Martin Feed Mills, Elmira, Ontario) $42 \%$ protein, and the amount of food consumed was recorded. 
Food pellets were distributed individually at different points in the tank and at different rates depending on the ingestion rates of the fish. Satiety was considered to be reached when 2 pellets had reached the bottom of the tank or feeding had continued for $10 \mathrm{~min}$. Food consumed in a given week was expressed as a percentage of initial body weight (\% b.w.). After $2 \mathrm{wk}$, fish in Groups A, C, and E were anesthetized with 2-phenoxylethanol and each fish was injected intraperitoneally (i.p.) with approximately 20000 Cryptobia salmositica in $0.1 \mathrm{ml}$ phosphate-buffered saline (PBS), while each fish in Groups B and D was injected i.p. with $0.1 \mathrm{ml}$ of PBS. In Group E, 4 to 5 fish were killed weekly by a blow to the head, the caudal peducle was severed, and blood was collected with an heparinized syringe. Parasitemia was determined with a hemocytometer (Archer 1965), and PCV with a hematocrit centrifuge.

$X$-radiography-feed intake, gastric evacuation rate, and feeding hierarchy: Once a week, fish in Groups A to D were fed food that contained 5\% ferrospheres ( $0.45 \mathrm{~mm}$ diameter; Draiswerke). The beads did not affect the palatability of the food, as there was no obvious change in food consumption. The fish were anesthetized $1 \mathrm{~h}$ after feeding with 2-phenoxyethanol, and x-rayed using an acu-ray HFJ series, universal portable X-ray (Sterne Equipment) at $50 \mathrm{kV}, 1.05 \mathrm{~mA} \mathrm{~s}$ at $83 \mathrm{~cm}$. The food intake of each fish was quantified by relating the number of beads found in its stomach to a standard curve $\left(\mathrm{r}^{2}=0.99, \mathrm{n}=16\right)$ (Jobling et al. 2000). Fish were again $\mathrm{x}$-rayed $48 \mathrm{~h}$ later, and the remaining beads counted to estimate the amount of food cleared. Gastric evacuation (GE) of food was expressed as \% beads cleared through the gastrointestinal tract after $48 \mathrm{~h}: \mathrm{GE}_{48 \mathrm{~h}}=\left(\right.$ beads $_{0 \mathrm{~h}}-$ beads $\left._{48 \mathrm{~h}}\right) /$ beads $_{0 \mathrm{~h}}$. The $48 \mathrm{~h}$ period was chosen because (1) it maximized the time period between $\mathrm{x}$-rays (minimizing stress without disrupting the feeding time), and (2) a preliminary timecourse experiment had shown that $67 \%$ of juvenile rainbow trout maintained at $10^{\circ} \mathrm{C}$ (and fed once daily to satiation) had evacuated detectable beads at $48 \mathrm{~h}$.

The hierarchy within Groups A to D was determined before and after the onset of anorexia in infected groups (A and C) by correlating the mean share of meal (MSM, a measure of how food was partitioned within the group) and coefficient of variation in food intake (CV) to determine the position of individual fish within the hierarchy of each group (McCarthy et al. 1992). MSM was calculated as: $M S M x=$ no. of beads ingested by fish $x$ /total no. of beads ingested by group. $\mathrm{CV}$, a measure of variability in food consumption from meal to meal by each individual fish was calculated by counting the number of beads ingested (x-radiographs) after feeding: $\mid \mathrm{CVI}=$ avg. food eaten (massspecific)/SD (avg. food eaten).
Expt 2: Role of anorexic diet in immune response of juvenile rainbow trout to live Cryptobia salmositica vaccine. Experimental design: In the week when anorexia was first detected (as significant difference in food intake between infected and naïve groups) in infected fish (Group A) at $10^{\circ} \mathrm{C}$ (3 w.p.i.), the amount of food eaten in that week was averaged $\left(0.94 \%\right.$ b.w. $\left.\mathrm{d}^{-1}\right)$ and this amount was then fed to Group F (pair-fed) for the duration of this experiment. Group F was fed this diet for $4 \mathrm{wk}$ before vaccination. Groups $\mathrm{G}$ and B were pair-fed (Group B being the naïve control). The fish in Groups F and G were each vaccinated i.p. with 20000 attenuated C. salmositica in $0.1 \mathrm{ml}$ PBS. From Groups $\mathrm{F}, \mathrm{G}$, and $\mathrm{B}, 2$ to 4 individuals were sacrificed weekly from 2 to 6 wk post-vaccination (w.p.v.) to determine cell-mediated and/or humoral immune response.

Cell-mediated immune response-macrophage isolation and respiratory-burst assay: Macrophages were isolated from the head kidney, and a respiratoryburst assay was performed (Secombes 1990). Briefly, fish were sacrificed with a blow to the head and bled dry via the caudal vein. The anterior kidney was dissected out aseptically, placed in $5 \mathrm{ml}$ Leibovitz media (L-15) (Sigma) containing 2\% fetal bovine serum (FBS, Gibco), heparin (10 $\mathrm{U} \mathrm{ml}^{-1}$, Fisher), and penicillin (100 $\left.\mu \mathrm{g} \mathrm{m} \mathrm{m}^{-1}\right)$ /streptomycin $\left(100 \mathrm{U} \mathrm{ml}^{-1}\right)(\mathrm{P} / \mathrm{S}$, Sigma) in a Petri dish. The head kidney was cut into fine pieces with scissors and the suspension was pipetted onto a $100 \mu \mathrm{m}$ cell-sieve and pushed gently through and into a centrifuge tube. The resulting suspension was carefully layered onto a 34 to $51 \%$ Percoll (Amersham) density gradient, and centrifuged at $400 \times g$ for $40 \mathrm{~min}$ at $4{ }^{\circ} \mathrm{C}$. Cells were collected from the 34 to $51 \%$ interface, which was greatly enriched with macrophages. Cell viability was determined using $0.4 \%$ trypan blue (Sigma) in PBS, and the cell suspension was adjusted to $5 \times 10^{6}$ living cells $\mathrm{ml}^{-1}$ with L-15, $0.1 \% \mathrm{FBS}$ and P/S. A volume $(100 \mu \mathrm{l})$ of the cell suspension was placed into each well of a cell culture-grade 96-well microtiter plate (Corning) for $3 \mathrm{~h}$ to enable the cells to adhere and form a monolayer at $14^{\circ} \mathrm{C}$. Adhered macrophages were then washed with L-15 and incubated overnight with L-15 supplemented with $5 \%$ FBS at $14^{\circ} \mathrm{C}$. Macrophages from each fish were subjected to the following treatments in triplicate: $100 \mu \mathrm{l}$ of phorbol myristate acetate (PMA) at $1 \mathrm{mg} \mathrm{ml}^{-1}$ (Sigma), Cryptobia salmositica lysate (antigen) at $5 \mu \mathrm{g} \mathrm{ml}^{-1}$ (Mehta \& Woo 2002) and Hank's balanced salt solution (HBSS). Cells were incubated for $3 \mathrm{~h}$ at $14^{\circ} \mathrm{C}$ before addition of $100 \mu \mathrm{l}$ nitroblue tetrazolium (NBT) at $1 \mathrm{mg} \mathrm{ml}^{-1}$ in HBSS for 2 $\mathrm{h}$ at $14^{\circ} \mathrm{C}$. The supernatant was removed, and the cells were fixed in $100 \%$ methanol and allowed to air-dry. During incubation, activated macrophages produced $\mathrm{O}_{2}^{-}$, which reacted with NBT to produce insoluble blue formazan. Formazan was dissolved using $80 \mu \mathrm{l} 2 \mathrm{M}$ 
$\mathrm{KOH}$ and $93 \mu$ l dimethyl sulfoxide (DMSO, Sigma). The turquoise-blue solution was read on a multiscan spectrophotometer (Molecular Devices, MAXline microplate reader). The stimulation index (SI) was calculated as the ratio of triggered (with PMA or Antigen) to non-triggered (HBSS) optical-density (OD) readings.

Humoral immune response: enzyme-linked immunosorbent assay (ELISA): The method of Sitja-Bobbadilla \& Woo (1994) was used with some modifications. Each well of 96-well flat-bottomed, high-binding polystyrene plates (Corning, USA) was coated with $50 \mu \mathrm{l}$ of attenuated Cryptobia salmositica lysate (25 $\mu \mathrm{g}$ protein $\mathrm{ml}^{-1}$ ), diluted in a carbonate-bicarbonate buffer ( $\mathrm{pH}$ 9.6), and incubated overnight at $5^{\circ} \mathrm{C}$. Unbound antigen was removed by washing 5 times with washing buffer (PBS + 0.05\% Tween-20). A volume of $200 \mu \mathrm{l}$ of blocking buffer (5\% skim milk [w/v] in PBS) was added to each well and incubated at room temperature for $30 \mathrm{~min}$ followed by washing. Test plasma $(50 \mu \mathrm{l})$ from sacrificed fish was added to each well in duplicate and incubated for $1 \mathrm{~h}$ at room temperature and then washed. Rabbit anti-salmon immunoglobulin (courtesy of K. Buchmann, Royal Veterinary \& Agricultural College, Denmark), diluted 1:1000 in dilution buffer (PBS $+0.01 \%$ bovine serum albumin), was added to each well (50 $\mu \mathrm{l})$, incubated for $1 \mathrm{~h}$ at room temperature, and then washed. This was followed by addition of $50 \mu \mathrm{l}$ of peroxidase-conjugated goat anti-rabbit immunoglobulin (Sigma Aldrich) diluted 1:10000 in dilution buffer, incubated for $1 \mathrm{~h}$ at room temperature and then washed. The substrate $o$-phenyledamine (Sigma Aldrich) was added (50 $\mu \mathrm{l})$ to

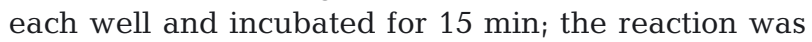
stopped with $50 \mu \mathrm{l}$ of $3 \mathrm{M} \mathrm{HCl}$. The optical density in each well was read at $492 \mathrm{~nm}$ using a microplate reader (Molecular Devices).

Statistical analysis. A 1-way ANOVA was used to compare between treatment groups each week. If variance was not equal among treatment groups, Kruskal-Wallis 1-way ANOVA on ranks was applied. Repeated-measures ANOVAs were used to compare changes in $\mathrm{GE}_{48 \mathrm{~h}}$ as a function of treatment time. If a significant difference was found in the ANOVAs, Tukey's SD test or Dunn's test (ANOVA on ranks) were used for multiple pairwise comparison. Pearson's test was used to determine correlations between initial weight, MSM and CV. Significance was determined if $\mathrm{p}<0.05$.

\section{RESULTS}

Expt 1: Food consumption, gastric evacuation, and feeding hierarchy in infected juvenile rainbow trout at 10 and $5^{\circ} \mathrm{C}$

Food consumption

At $10^{\circ} \mathrm{C}$, there was no significant difference in food consumption between infected (Group A) and naïve (Group B) groups until 3 w.p.i., when Group A had a
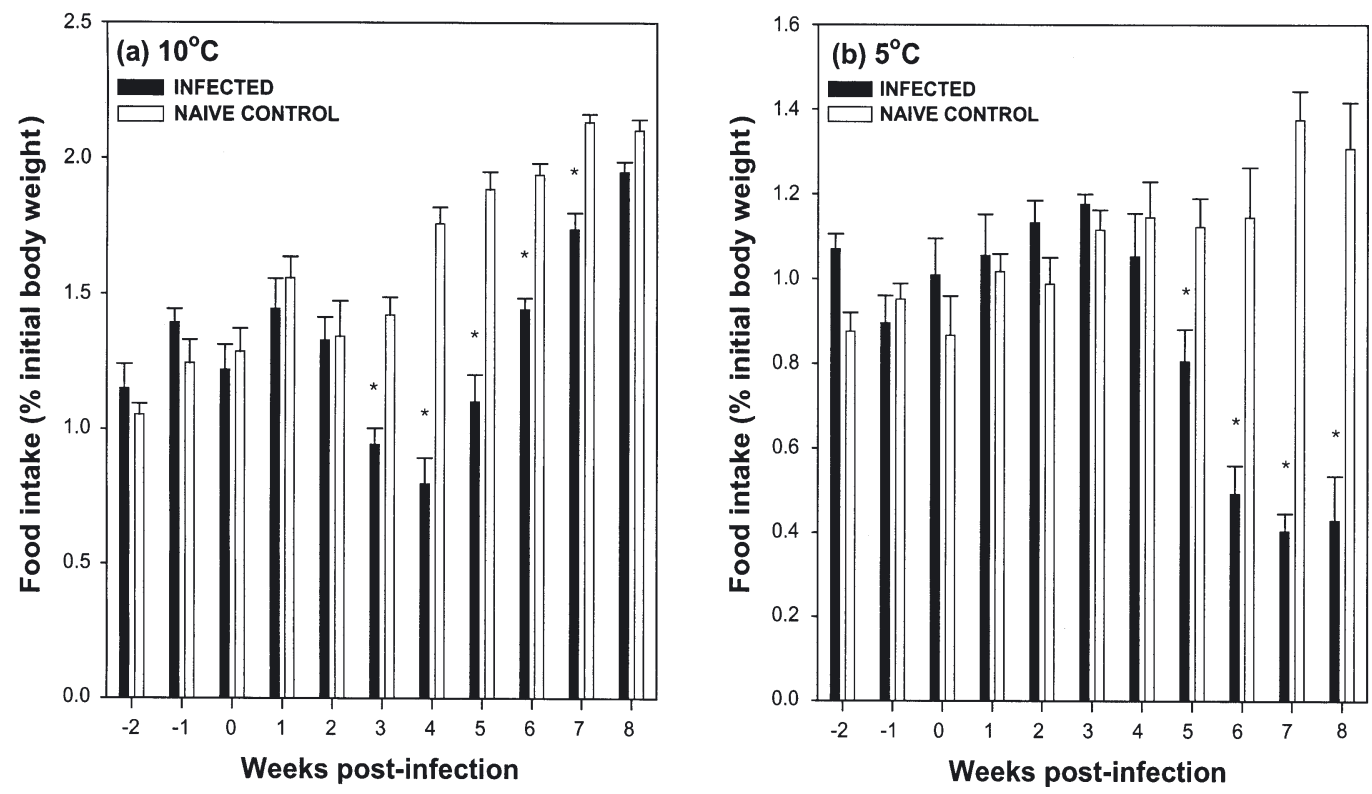

Fig. 1. Oncorhynchus mykiss infected with Crypotobia salmositica. Food intake (weekly mean \pm SE; \% of initial body weight) by juveniles ( $\mathrm{n}=13$ group $^{-1}$ dose of 20000 parasites fish ${ }^{-1}$ ) and naïve controls at (a) $10^{\circ} \mathrm{C}$ and (b) $5^{\circ} \mathrm{C}$. * Significantly lower than naïve controls 
significantly lower $(p=0.005)$ food consumption than Group B (0.94 and $1.42 \%$ b.w. respectively; Fig. 1a). Food consumption in Group A continued to be significantly lower until 7 w.p.i. Anorexia was most severe at 4 w.p.i. $(0.80 \%$ b.w.), and at 8 w.p.i. there was no significant difference in food consumed between Groups A and B. During the anorexic period, all fish in Group A had ingested some food (data based on xradiographs).

Fish at $5^{\circ} \mathrm{C}$ consistently consumed less food than fish at $10^{\circ} \mathrm{C}$. Group $\mathrm{C}$ (infected) had significantly lower $(\mathrm{p}<0.001)$ food consumption than Group D ( 0.81 and $1.14 \%$ b.w. respectively) at 5 w.p.i. until the end of the study at 8 w.p.i. (Fig. 1b). Complete absence of food was detected in 2 of 12 fish at 6 w.p.i., in 7 of 12 fish at 7 w.p.i., and in 5 of 12 fish at 8 w.p.i. Mean weekly food consumption was lowest at 7 w.p.i. $(0.40 \%$ b.w.).

$\mathrm{X}$-radiography confirmed that fish at $10^{\circ} \mathrm{C}$ became anorexic from 4 to 8 w.p.i., while fish at $5^{\circ} \mathrm{C}$ were anorexic from 5 w.p.i. until the end of the experiment.

Mortalities, parasitemia and PCV

At $10^{\circ} \mathrm{C}$, parasites were detected in 5 of 5 fish (Group E) from 2 to 8 w.p.i. and were still detectable at 9 w.p.i. in 3 of 4 fish; 1 fish died at 5 w.p.i. in this group. Parasitemia increased sharply from 2 w.p.i., peaked at 4 w.p.i. $\left(9.6 \times 10^{6}\right.$ parasites $\mathrm{ml}^{-1}$ blood $)$ and declined thereafter (Fig. 2). PCV decreased sharply from $33.3 \%$ at 3 w.p.i. to its lowest value of $18.0 \%$ at 5 w.p.i. (Fig.2). At 9 w.p.i., fish displayed $24.4 \%$ PCV.

At $5^{\circ} \mathrm{C}, 2$ fish died at 8 w.p.i. The dead fish displayed splenomegaly and contained large numbers of Cryptobia salmositica in the head kidney. The group was still anorexic and displayed high parasiteamia $\left(4.2 \times 10^{6}\right.$ parasites $\mathrm{ml}^{-1}$ blood), and low PCV (10.8\%) at 9 w.p.i. (Fig. 2).

\section{Gastric evacuation (GE)}

The $\mathrm{GE}_{48 \mathrm{~h}}$ in both infected and naïve groups decreased gradually at both temperatures. The difference between $\mathrm{GE}_{48 \mathrm{~h}}$ at -1 and 8 w.p.i. was significant in Groups A, B, and D. In Group C there was a significant difference between $\mathrm{GE}_{48 \mathrm{~h}}$ at 7 and 8 w.p.i., but some $\mathrm{GE}_{48 \mathrm{~h}}$ values were missing, as 7 of 12 and 5 of 12 fish had not ingested food at these times respectively. Fish at $5^{\circ} \mathrm{C}$ consistently had a much lower $\mathrm{GE}_{48 \mathrm{~h}}$ than fish at $10^{\circ} \mathrm{C}$ (Fig. 3). At $10^{\circ} \mathrm{C}$, there was no significant difference between infected (A) and uninfected (B) groups during the course of the experiment. At $5^{\circ} \mathrm{C}$, the infected group (Group C) had a significantly higher

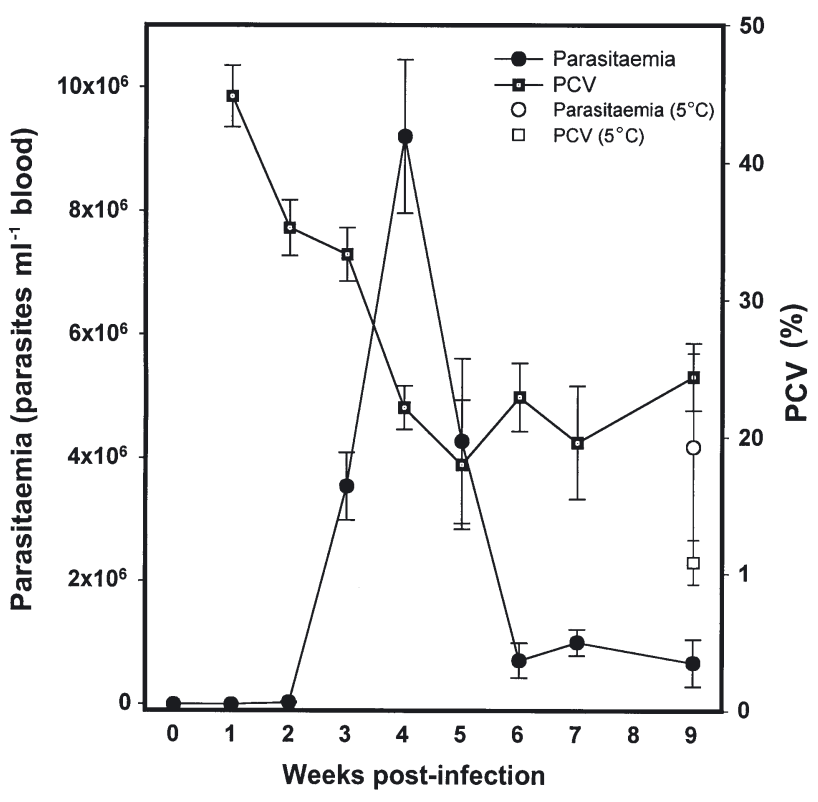

Fig. 2. Oncorhynchus mykiss infected with Cryptobia salmositica. Parasitemia and pack cell volume (PCV) values (mean $\pm \mathrm{SE}$ ) of juveniles ( $\mathrm{n}=5$ per sample) infected with 20000 C. salmositica over the course of infection at $10^{\circ} \mathrm{C}$ (solid symbols); open symbols: values at $5^{\circ} \mathrm{C}$ at $9 \mathrm{wk}$ postinfection

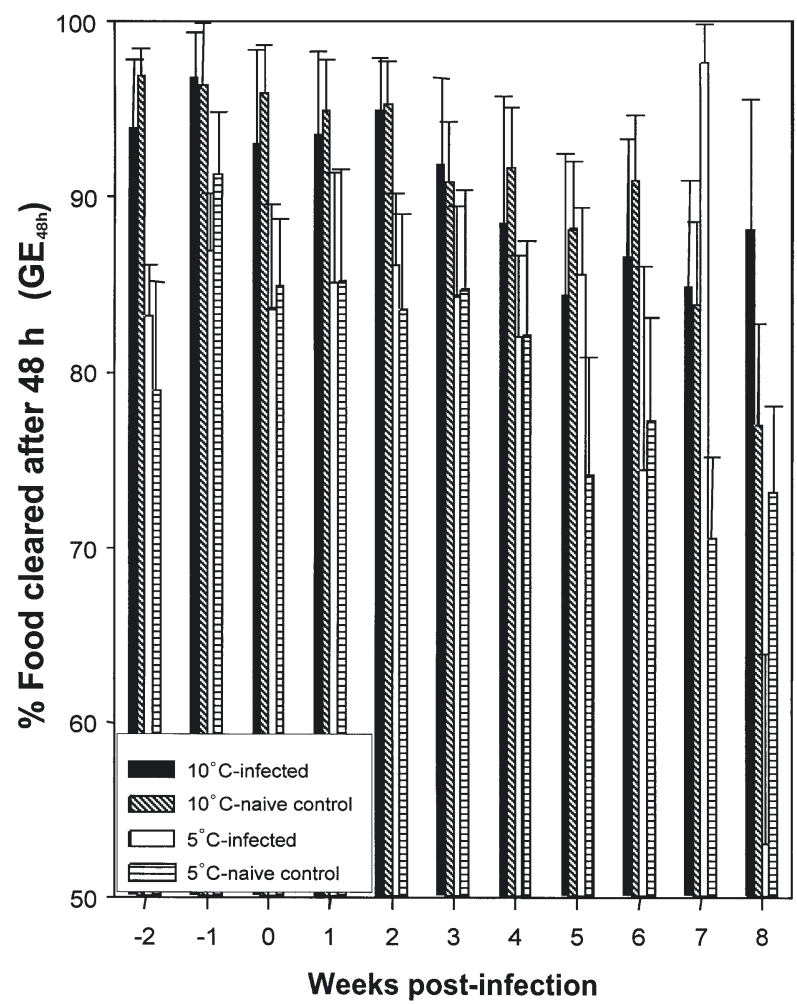

Fig. 3. Oncorhynchus mykiss infected with Cryptobia salmositica. Food cleared (mean percentage \pm SE) by juveniles at 10 and $5^{\circ} \mathrm{C}$ after $48 \mathrm{~h}\left(\mathrm{n}=13\right.$ group $\left.^{-1}\right)$ 
$\mathrm{GE}_{48 \mathrm{~h}}(\mathrm{p}<0.05)$ than the uninfected group (D) at 7 w.p.i., but this could have been skewed, as 7 of 12 fish had not fed.

\section{Feeding hierarchy}

Relationships between MSM, b.w., and CV were examined using x-radiography before and after onset of anorexia. Infected fish at both temperatures had a higher, but not significant, CV compared to their naïve counterparts. There were significant positive correlations between MSM and b.w. before the onset of anorexia in all groups. This significant correlation was maintained during the anorexic period in Groups A and D but not in Groups B ( $p=0.162)$ and C ( $p=0.942)$ (Table 1). Group B displayed the least variation in b.w. within the group, and this would explain the lack of any obvious feeding hierarchy.

There were no significant correlations between MSM and CV before anorexia in Groups A, B, and C. The correlation in Group D was significant $(\mathrm{p}=$ $0.0126)$, but 1 fish had not ingested food in 5 of the $7 \mathrm{wk}$, resulting in an extremely high CV value (198.04) compared to the mean CV of the other 12 fish (35.12). Were the data from this fish removed from the analysis, then the correlation in Group D would not be significant $(\mathrm{p}=0.104)$. During the anorexic period, neither of the uninfected groups (B and D) showed significant correlations, but both infected groups (A and C) did ( $p=0.0168$ and $p=0.0435$ respectively). No significant correlations were found between b.w. and CV in any groups.

\section{Expt 2: Role of anorexic diet in immune response of juvenile rainbow trout to live Cryptobia salmositica vaccine}

Respiratory-burst assay

There were no significant differences in the stimulation index (SI) between macrophages from vaccinated and naïve fish, although the SIs of macrophages from vaccinated fish were generally higher (Fig. 4), and vaccinated fish also consistently yielded a greater number of macrophages. PMA consistently produced a higher SI than the Cryptobia salmositica antigen (ag) in both vaccinated and naïve fish (Fig. 4a). The SI produced by ag was often below 1 (Fig. 4b). In vaccinated fish, the SI with PMA was significantly higher than that with ag at 3 and 6 w.p.i. ( $p<0.001$ and $p<$ 0.05 respectively). Vaccinated fish on both diets displayed the highest SI with PMA at 4 w.p.v. There were no significant differences in SI with PMA or ag between fish fed to satiation and fish fed an 'anorexic diet'.

\section{ELISA}

Antibodies against Cryptobia salmositica were detected at 2 w.p.v. Vaccinated fish had consistently higher antibody titers than uninfected controls. This difference was significant $(\mathrm{p}<0.05)$ at 2,4 , and 5 w.p.v. However, there was no difference in antibody titer between fish fed to satiation and fish fed an anorexic diet.

Table 1. Oncorhynchus mykiss. Initial weight ( $\mathrm{g}$ ) and correlation analysis of mean share of meal (MSM) with initial body weight (b.w.), and with coefficient of variation (CV) in food intake before and after onset of anorexia in juveniles infected with Cryptobia salmostica and in naïve controls at 10 and $5^{\circ} \mathrm{C}$. w.p.i.: weeks post-infection; ${ }^{*}$ significant at $\mathrm{p}<0.05$

\begin{tabular}{|c|c|c|c|c|c|}
\hline \multirow[t]{2}{*}{ (Group) treatment } & \multicolumn{2}{|c|}{ Initial wt (g) } & \multirow{2}{*}{$\begin{array}{c}\mathrm{CV}(\%) \\
\text { Mean } \pm \mathrm{SE}\end{array}$} & \multicolumn{2}{|c|}{ Correlation (p-value) of MSM with } \\
\hline & Mean \pm SE & Range & & b.w. & $\mathrm{CV}$ \\
\hline (A) Infected, $10^{\circ} \mathrm{C}$ (all) & $60.1 \pm 5.0$ & $30.4-89.3$ & $40.2 \pm 3.1$ & $0.0019^{*}$ & $0.0098^{*}$ \\
\hline before anorexia ( -2 to 3 w.p.i.) & & & $27.9 \pm 3.0$ & $0.0050^{*}$ & 0.37 \\
\hline after anorexia ( 4 to 8 w.p.i.) & & & $50.1 \pm 4.4$ & $0.0013^{*}$ & $0.0168^{*}$ \\
\hline (B) Naïve, $10^{\circ} \mathrm{C}$ (all) & $57.0 \pm 3.3$ & $38.4-72.7$ & $36.9 \pm 4.0$ & 0.068 & 0.273 \\
\hline-2 to 3 w.p.i. & & & $27.9 \pm 3.0$ & $0.0497^{*}$ & 0.279 \\
\hline 4 to 8 w.p.i. & & & $25.1 \pm 2.5$ & 0.162 & 0.886 \\
\hline (C) Infected, $5^{\circ} \mathrm{C}$ (all) & $58.9 \pm 4.3$ & $35.8-85.7$ & $57.6 \pm 5.2$ & 0.234 & $0.000655^{*}$ \\
\hline before anorexia ( -2 to 5 w.p.i.) & & & $30.7 \pm 2.1$ & $0.0338^{*}$ & 0.314 \\
\hline after anorexia (6 to 8 w.p.i.) & & & $144.5 \pm 35.8$ & 0.942 & $0.0435^{*}$ \\
\hline (D) Naïve, $5^{\circ} \mathrm{C}$ (all) & $57.1 \pm 3.1$ & $38.7-83.4$ & $47.0 \pm 9.2$ & $0.0117^{*}$ & $0.00679^{*}$ \\
\hline-2 to 5 w.p.i. & & & $47.6 \pm 12.9$ & $0.0177^{*}$ & $0.0126^{* a}$ \\
\hline 6 to 8 w.p.i. & & & $27.7 \pm 6.3$ & $0.0187^{*}$ & 0.165 \\
\hline
\end{tabular}



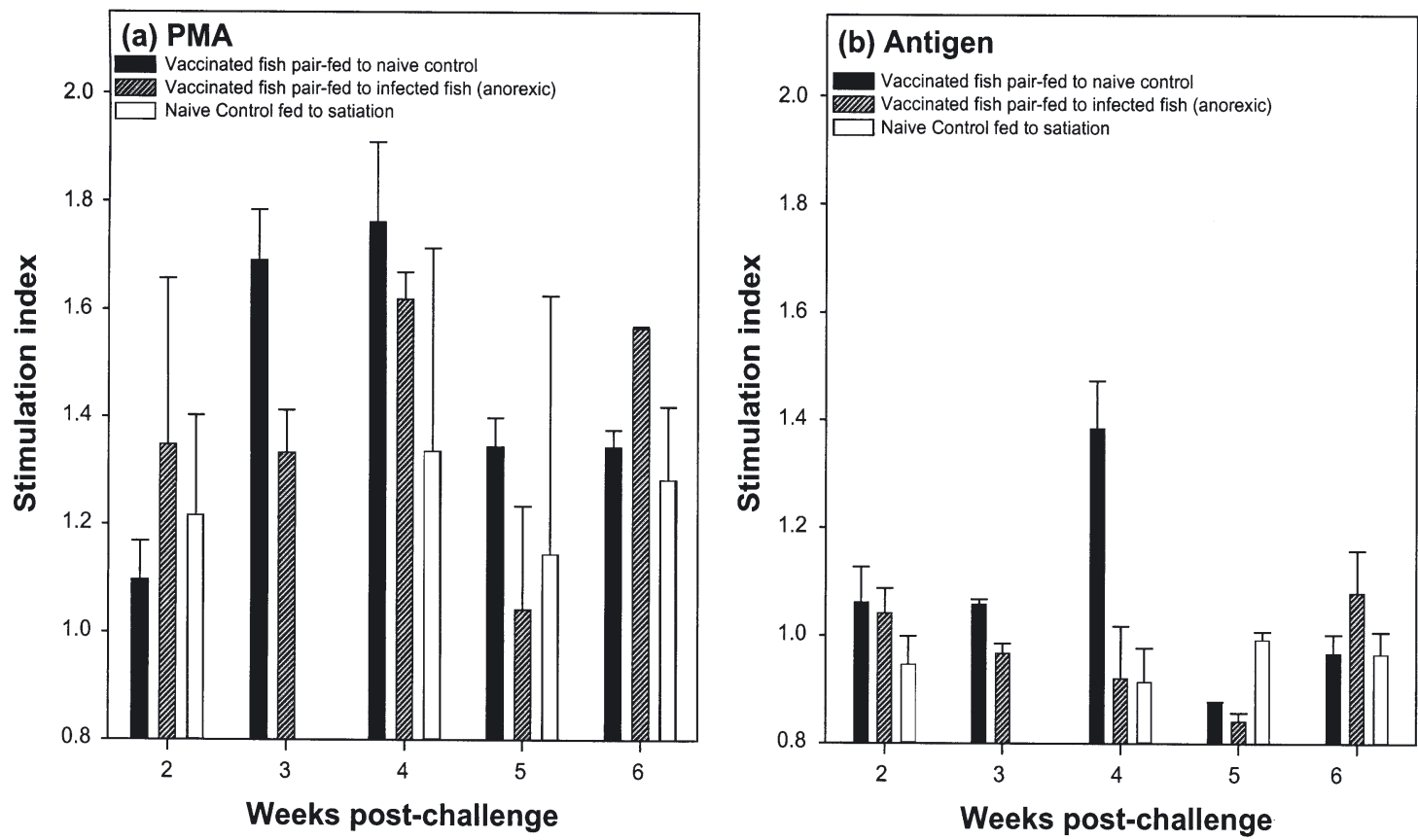

Fig. 4. Stimulation index (mean $\pm \mathrm{SE}$ ) of macrophages stimulated with (a) PMA and (b)Cryptobia salmositica lysate from fish that were vaccinated with a live $C$. salmositica vaccine

\section{DISCUSSION}

Anorexia occurred in rainbow trout infected with Cryptobia salmositica at both 10 and $5^{\circ} \mathrm{C}$ and this was confirmed using x-radiography. The onset of anorexia coincided with a significant rise in parasitemia and a decrease in PCV at $10^{\circ} \mathrm{C}$. Fish at $10^{\circ} \mathrm{C}$ resumed normal food intake at 8 w.p.i., while fish at $5^{\circ} \mathrm{C}$ were still severely anorexic and anemic, with high parasitemia, at 9 w.p.i., the termination of this experiment. Additionally, 2 fish died from cryptobiosis at this time and temperature. These results confirm earlier studies on the relationship between increasing parasitemia and the onset of anemia and anorexia (Li \& Woo 1991, Thomas \& Woo 1992). Lysis of erythrocytes occurs through (1) a metalloprotease secreated by the parasite (Zuo \& Woo 1997, 2000), and/or (2) the formation of immune complexes on erythrocytes activating complement-mediated hemolysis (Thomas \& Woo 1988, 1989). Anemia is most evident during the acute stage of the disease (high parasitemia) and it is at this time that fish are more susceptible to environmental hypoxia (Wehnert \& Woo 1986), which is known to contribute to anorexia in fish (Kramer 1987, Jobling 1994). Acute disease incurs significantly higher bioenergetic costs (Beamish et al. 1996) and reduces the maximum scope aerobic activity (Kumaraguru et al. 1995).

Temperature affected the onset of anorexia, as fish kept at $10^{\circ} \mathrm{C}$ became anorexic at 3 w.p.i. while those at $5^{\circ} \mathrm{C}$ became anorexic at 5 w.p.i. Anorexia was much more severe at $5^{\circ} \mathrm{C}$ : the reduction in food intake was more pronounced and more than half the group ( 7 of 12) did not ingest food compared to fish at $10^{\circ} \mathrm{C}$, all of which had some food in their stomachs. Further studies are necessary to elucidate the effect of temperature on anorexia during cryptobiosis.

Woo et al. (1983) also found a longer latent period in fish at $5^{\circ} \mathrm{C}$. However, in contrast to this study, Woo et al. found that parasitemia in rainbow trout infected with Cryptobia salmositoica at $5^{\circ} \mathrm{C}$ was considerably lower than in fish infected at $10^{\circ} \mathrm{C}$, even $70 \mathrm{~d}$ postinfection. Similarly, goldfish Cassius auratus infected with another pathogenic hemoflagellate, Trypanasoma carrasi, were more susceptible to infection at $20^{\circ} \mathrm{C}$ than at $10^{\circ} \mathrm{C}$. At $5^{\circ} \mathrm{C}$, the parasite multiplied less readily until it became acclimated to its new temperature; thereafter, the parasitemia pattern became similar to that of fish at $10^{\circ} \mathrm{C}$. The susceptibility of fish to cryptobiosis at low temperatures should be further investigated.

Cryptobia salmosistica did not affect the $\mathrm{GE}_{48 \mathrm{~h}}$ in fish at either temperature. The $48 \mathrm{~h}$ period may have been too long, since different regions of the gastrointestinal tract have differential rates of evacuation (Tache et al. 2001). Olsson et al. (1999) found that stomach motility was greatly reduced in rainbow trout injected with the hormone cholecystokinin (CCK) which reduced gastric emptying of the stomach. In the present study, there 
were large differences in $\mathrm{GE}_{48 \mathrm{~h}}$ between individuals in each group. Olsson et al. (1999) reported similar results, with the evacuation rate of some fish displaying a linear trend, and that of others an exponential shape. Stress may reduce appetite through the anorexigenic effects of the CRF and related peptides which also activate the HPI axis (Bernier \& Peter 2001b). Although Laidley et al. (1988) found elevated cortisol levels in rainbow trout infected with C. salmositica; they were not significantly higher than in uninfected fish. These authors suggested that parasitemia did not activate the HPI axis. Recent studies in mammals (Tache et al. 2001) have shown that the delayed gastric evacuation induced by the CRF and related peptides is not related to activation of pituitary-adrenal hormones. The role of CRF-related peptides in mediating anorexia in C. salmositica infection or in the physiological regulation of gastric evacuation needs to be investigated.

MSM and CV can be used to assess social hierarchy in fish, with a negative correlation indicating a strong hierarchy (Jobling et al. 2000). McCarthy et al. (1992) found the correlation became stronger when food was given at lower rations and that larger fish were generally dominant (Sloman \& Armstrong 2002). In the present study, there were significant correlations between initial weight and MSM in all groups before anorexia. This correlation was not present in the uninfected group at $10^{\circ} \mathrm{C}$ (Group B) or the infected group at $5^{\circ} \mathrm{C}$ (Group C). The lack of a significant correlation for Group B might be due to low variations in body size in this group. Group $\mathrm{C}$ was more anorexic than infected fish at $10^{\circ} \mathrm{C}$ (Group A), and the increased severity of disease in Group $\mathrm{C}$ may have contributed to the loss of size effects on hierarchy. There were no correlations between MSM and CV before the onset of anorexia. This was expected, as the fish were fed to satiation, thereby reducing competition. During the anorexic period, which represents the acute stage of the disease, there were significant negative correlations between MSM and CV in infected groups, but not in naïve groups. The significant correlation in infected fish suggests that the feeding hierarchy was strengthened by infection. This may also indicate variability in susceptibility to cryptobiosis, with dominant fish becoming more dominant (higher MSM and lower CV) and subordinate fish becoming more subordinate. This is consistent with the hypothesis that subordinate fish are more susceptible to disease (Peters et al. 1988, Maule et al. 1989). The correlation between MSM and b.w. was maintained at $10^{\circ} \mathrm{C}$ but not at $5^{\circ} \mathrm{C}$. These results suggest that fish at $5^{\circ} \mathrm{C}$ are more severely affected by cryptobiosis, regardless of size or social status, while at $10^{\circ} \mathrm{C}$ the size hierarchy is maintained.
It has been hypothesized that, in parasitic infections, anorexia is beneficial to the host as it deprives parasites of nutrients, thereby affecting their survival and reproduction (Symons 1985, Li \& Woo 1991, Kyriazakis et al. 1998). Nutritional modulation of Cryptobia salmositica infection has been demonstrated by Thomas \& Woo (1990), and Li \& Woo (1991) found higher parasitemia and lower PCV in fish fed a highprotein diet than in fish fed a low-protein diet. Plasma protein levels were significantly higher in fish fed a high-protein diet $(52 \%)$ than in those fed a low-protein diet (37 and $22 \%$ ), and this has been shown to increase parasite multiplication in vitro (Li \& Woo 1991). Infected rainbow trout (on $37 \%$ protein diet) had a depressed humoral immune response to sRBCs (Wehnert \& Woo 1981, Jones et al. 1986, Thomas \& Woo 1992). Also, infected fish challenged with the bacterial pathogen Yersinia ruckeri suffered higher mortalities than naïve-controls, and infected fish had a significantly lower humoral immune response to the pathogen (Jones et al. 1986). Also, Thomas \& Woo (1992) found that anorexia during cryptobiosis contributes to immunodepression, since naïve fish pair-fed with infected fish displayed a significantly lower antibody production in response to sRBCs. However, in the present study, anorexia did not affect the fish's cellmediated or humoral immune response against live $C$. salmositica vaccine. This may have been the result of a combination of factors. For example, the continual antigenic stimulation provided by a live vaccine, compared to earlier studies which used sRBCs or a pathogen (Y. ruckeri) (Wehnert \& Woo 1981, Jones et al. 1986, Thomas \& Woo 1992). Also, the fish in the present study were fed a $42 \%$ protein diet compared to a $37 \%$ protein diet used in earlier studies. The higher protein diet would have increased plasma protein levels (Li \& Woo 1991), and this increase might also have contributed to the lack of immunodepression in fish on an anorexic diet. Further studies are currently underway to test these hypotheses.

Respiratory-burst activity was higher in vaccinated fish than in naïve fish, but the difference was not statistically significant. Mehta \& Woo (2002) found a significantly higher respiratory burst activity in fish infected or vaccinated with pathogenic and attenuated strains of Cryptobia salmositica. Additionally, C. salmositica was found to be a potent stimulator of respiratory-burst activity akin to PMA. The present study found that C. salmositica antigen consistently produced a lower SI (sometimes below 1), suggesting that the parasite may inhibit cell-mediated functions.

In conclusion, there was delayed onset of anorexia in fish kept at $5^{\circ} \mathrm{C}$ compared to fish kept at $10^{\circ} \mathrm{C}$. At the lower temperature, anorexia was more prominent, PCV was lower, and feeding hierarchy was not main- 
tained. There was no difference in gastric evacuation of food over $48 \mathrm{~h}$, although the evaluation of gastric evacuation was not sensitive enough to detect regional differences in motility of the gastrointestinal tract (GIT). Cell-mediated and humoral immune responses to a live vaccine were not depressed in fish (on a $42 \%$ protein diet) fed the amount of food anorexic fish would eat. Cryptobiosis is ideal for studying changes in appetite-regulation, since Cryptobia salmositica infection induces anorexia in rainbow trout. Further work is needed to elucidate the mechanisms of anorexia and its relationship to immunodepression. This would include clarifying neuroendocrine pathways related to anorexia induced by infectious and non-infectious agents, and identifing regional differences in food evacuation in the GIT to better differentiate the effect of stress and/or disease on gut motility.

\section{LITERATURE CITED}

Archer RK (1965) Haematological techniques for use on animals. Blackwell Scientific, Oxford

Ardelli BF, Woo PTK (1997) The protective immune response of Salvelinus fontinalis and susceptibility of Salvelinus namavcush to the hemoflagellate, Cryptobia salmositica. J Parasitol 83:943-946

Ardelli BF, Woo PTK (2002) Experimental Cryptobia salmositica (Kinetoplastida) infections in Atlantic salmon, Salmo salar L.: cell-mediated and humoral immune responses against the pathogenic and vaccine strains of the parasite. J Fish Dis 25:265-274

Barton BA, Iwama GK (1991) Physiological changes in fish from stress in aquaculture with emphasis on the response and effects of corticosteroids. Annu Rev Fish Dis 1:3-26

Beamish FWH, Sitja-Bobadilla A, Jebbink JA, Woo PTK (1996) Bioenergetic cost of cryptobiosis in fish: rainbow trout Oncorhynchus mykiss infected with Cryptobia salmositica and with an attenuated live vaccine. Dis Aquat Org 25:1-8

Bernier NJ, Peter RE (2001a) The hypothalamic-pituitaryinterrenal axis and the control of food intake in teleost fish. Comp Biochem Physiol B129: 639-644

Bernier NJ, Peter RE (2001b) Appetite-suppressing effects of urotensin I and corticotrophin-releasing hormone in goldfish (Carassius auratus). Neuroendocrinology 73:248-260

Damsgard B, Mortensen A, Sommer AI (1998) Effects of infectious pancreatic necrosis virus (IPNV) on appetite and growth in Atlantic salmon, Salmo salar L. Aquaculture 163:185-193

Dezfuli BS, Giari L, Arrighi S, Domeneghini C, Bosi G (2003) Influence of enteric helminths on the distribution of intestinal endocrine cells belonging to the diffuse endocrine system in brown trout, Salmo trutta L. J Fish Dis 26:155-166

Ebbersen P, Villadsen JA, Villadsen HD, Heller KE (1992) Effect of social order, lack of social hierarchy, and restricted feeding on murine survival and virus leukemia. Ann NY Acad Sci 673:46-52

Feng S, Woo PTK (1996) Cell-mediated immune response and T-like cells in thymectomized Oncorhynchus mykiss (Walbaum) infected with or vaccinated against the pathogenic hemoflagellate Cryptobia salmositica Katz 1951. Dis Aquat Org 28:211-219
Jobling M (1994) Fish bioenergetics. Chapman \& Hall, London Jobling M, Coves D, Damsgaard B, Kristiansen HR, Koskela J, Petersdottir TE, Kadri S, Gudmundsson O (2000) Techniques for measuring food intake. In: Houlihan D, Boujard $\mathrm{T}$, Jobling $\mathrm{M}$ (eds) Food intake in fish. Blackwell Science, Oxford, p 49-88

Jones SRM, Woo PTK (1987) The immune response of rainbow trout, Salmo gairdneri Richardson to the haemoflagellate, Cryptobia salmositica Katz 1951. J Fish Dis 10: 395-402

Jones SRM, Woo PTK, Stevenson RMW (1986) Immunosuppression in Salmo gairdneri caused by the haemoflagellate, Cryptobia salmositica. J Fish Dis 9:931-938

Kramer DL (1987) Dissolved oxygen and fish behaviour. Environ Biol Fish 18:81-92

Kumaraguru A, Beamish FWH, Woo PTK (1995) Impact of a pathogenic haemoflagellate, Cryptobia salmositica Katz, on the metabolism and swimming performance of rainbow trout, Oncorhynchus mykiss (Walbaum). J Fish Dis 18: 297-305

Kyriazakis I, Tolkamp BJ, Hutchings MR (1998) Towards a functional explanation for the occurrence of anorexia during parasitic infections. Anim Behav 56:265-274

Laidley CW, Woo PTK, Leatherland JF (1988) The stressresponse of rainbow trout to experimental infection with the blood parasite Crypotobia salmositica Katz, 1951. J Fish Biol 32:253-261

Lederis K, Fryer JN, Okawara Y, Schonrock C, Richter D (1994) Corticotropin-releasing factors acting on the fish pituitary: experimental and molecular analysis. In: Sherwood NM, Hew CL (eds) Fish physiology, Vol XIII. Molecular endocrinology of fish. Academic Press, San Diego, p 67-100

Li S, Woo PTK (1991) Anorexia reduces the severity of of cryptobiosis in Oncorhynchus mykiss. J Parasitol 77:467-471

Li S, Woo PTK (1995) Efficacy of a live Cryptobia salmositica vaccine, and the mechanism of protection in vaccinated rainbow trout Oncorhyncus mykiss, against cryptobiosis. Vet Immunol Immunopathol 48:343-353

Maule AG, Tripp RA, Kaatari SL, Shreck CB (1989) Stress alters immune function and disease resistance in chinook salmon (Oncorhynchus tshawytscha). J Endocrinol 120: 135-142

McCarthy ID, Carter CG, Houlihan DF (1992) The effect of hierarchy on individual variability in daily feeding of trainbow trout, Oncorhynchus mykiss (Walbaum). J Fish Biol 41:257-263

Mehta M, Woo PTK (2002) Acquired cell-mediated protection in rainbow trout, Oncorhynchus mykiss, against the hemoflagellate, Cryptobia salmositica. Parasitol Res 88: 956-962

Neji H, de la Noue J (1998) Effect of animal and vegetal protein diets on feed intake and apparent digestibility of nutrients in rainbow trout (Oncorhynchus mykiss) infected by Aeromonas salmonicida, with and without hypoxic stress. Can J Fish Aquat Sci 55:2019-2027

Olsson C, Aldman G, Larsson A, Holmgren S (1999) Cholecystokinin affects gastric emptying and stomach motility in the rainbow trout Oncorhynchus mykiss. J Exp Biol 202: 161-170

Padgett DA, Sherida, JF, Dorne J, Berntson GG, Candelora J, Glaser R (1998) Social stress and the reactivation of latent herpes simplex virus type 1. Proc Natl Acad Sci 95: 7231-7235

Peters G, Faisal M, Lang T, Ahmed I (1988) Stress caused by social interaction and its effect on susceptibility to Aeromonas hydrophila infection in rainbow trout Salmo gairdneri. Dis Aquat Org 4:83-89 
Pirhonen J, Schreck CB, Gannam A (2000) Appetite of chinook salmon (Oncorhynchus tshawytscha) naturally infected with bacterial kidney disease. Aquaculture 189: $1-10$

Schreck CB (1996) Immunomodulation: endogenous factors. In: Iwama GW, Nakanishi T (eds) The fish immune system: organism, pathogen, and environment. Academic Press, San Diego, p 311-337

Schreck CB, Olla BL, Davis MW (1997) Behavioural responses to stress. In: Iwama GW, Pickering AD, Sumpter JP, Schreck CB (eds) Fish stress and health in aquaculture. Society for Experimental Biology Seminar Series 62 . Cambridge University Press, Cambridge, p 145-170

Secombes C (1990) Isolation of salmonid macrophages and analysis of their killing activity. In: Stolen JS, Fletcher TC, Anderson DP, Roberson BS, van Muiswinkel WB (eds) Techniques in fish immunology, Vol 1. SOS Publications, Fair Haven, CT, p 137-154

Sitja-Bobbadilla A, Woo PTK (1994) An enzyme-linked immunosorbent assay (ELISA) for the detection of antibodies against the pathogenic haemoflagellate, Cryptobia salmositica Katz, and protection against juvenile rainbow trout, Oncorhynchus mykiss (Walbaum), inoculated with a live vaccine. J Fish Dis 17:399-408

Sloman KA, Armstrong JD (2002) Physiological effects of dominance hierarchies: laboratory artifacts or natural phenomena? J Fish Biol 61:1-23

Staines GJ, Woo PTK (1997) Immunization of susceptible chinook salmon, Oncorhynchus tshawytscha, against cryptobiosis. Bull Can Soc Zool 28:123-124

Symons LEA (1985) Anorexia. In: Baker JR, Muller R (eds) Advances in parasitology, Vol 24. Academic Press, London, p 103-135

Tache Y, Martinez V, Million M, Wang L (2001) Stress and the gastrointestinal tract. III. Stress-related alterations of gut motor function: role of brain corticotrophin-releasing factor receptors. Am J Physiol Gastrointest Liver Physiol 280: G173-G177

Thomas PT, Woo PTK (1988) Cryptobia salmositica: an in vitro study on the mechanism of anaemia in infected rainbow trout, Salmo gairdneri Richardson. J Fish Dis 11:425-431

Editorial responsibility: Wolfgang Körting,

Hannover, Germany
Thomas PT, Woo PTK (1989) An in vitro study on the hemolytic components from Cryptobia salmositica (Sarcomastigophora: Kinetoplastida). J Fish Dis 12:389-393

Thomas PT, Woo PTK (1990) In vivo and in vitro cell-mediated immune responses of Oncorhynchus mykiss against Cryptobia salmositica (Sarcomastigophora: Kinetoplastida). J Fish Dis 13:423-433

Thomas PT, Woo PTK (1992) Anorexia in rainbow trout, Oncorhynchus mykiss (Walbaum), infected with Cryptobia salmositica (Sarcomastigophora: Kinetoplastida): its onset and contribution to immunodepression. J Fish Dis 15:443-447

Wehnert SD, Woo PTK (1981) The immune responses of Salmo gairdneri during Trypanaplasma salmositica infection. Bull Can Soc Zool 11:100

Wehnert SD, Woo PTK (1986) Cryptobia salmositica: susceptibility of infected rainbow trout, Salmo gairdneri, to environmental hypoxia. J Parasitol 72:392-396

Wendelaar Bonga, SE (1997) The stress response in fish. Physiol Rev 77:591-625

Woo PTK (1978) The division process of Cryptobia salmositica in experimentally infected rainbow trout (Salmo gairdneri). Can J Zool 56:1514-1518

Woo PTK (1979) Trypanoplasma salmositica, experimental infections in rainbow trout, Salmo gairdneri. Exp Parasitol 47:36-48

Woo PTK (2001) Cryptobiosis and its control in North American fishes. Int J Parasitol 31:566-574

Woo PTK, Li S (1990) In vitro attenuation of Cryptobia salmositica and its use as a live vaccine against cryptobiosis in Oncorhynchus mykiss. J Parasitol 76:752-755

Woo PTK, Wehnert SD, Rodgers D (1983) The susceptibility of fishes to haemoflagellates at different ambient temperatures. Parasitology 87:385-392

Zuo X, Woo PTK (1997) Purified metallo-protease from the pathogenic Cryptobia salmositica and its in vitro proteolytic activites. Dis Aquat Org 30:177-185

Zuo X, Woo PTK (2000) In vitro hemolysis of piscine erythrocytes by purified metallo-protease from the pathogenic haemoflagellate, Cryptobia salmositica Katz. J Fish Dis 23: $227-230$

Submitted: June 27, 2003; Accepted: September 30, 2003 Proofs received from author(s): January 2, 2004 